\title{
Entre lançadeiras, guindastes e trilhos: doenças e acidentes de trabalho em Salvador nas décadas de 1930 e 1940.
}

\author{
Maria Elisa Lemos Nunes da Silva*
}

Resumo: o presente artigo discute as doenças e os acidentes de trabalho que ocorreram em Salvador nas décadas de 1930 e 1940. Tendo como fonte principal os processos de indenização, buscou-se construir o perfil do trabalhador e conhecer os acidentes e seus desdobramentos. Palco de controvérsias e de disputas, as ações de indenização possibilitaram observar diferentes aspectos da classe trabalhadora.

Palavras-chave: doenças; acidentes; trabalho.

Abstract: this article discusses the diseases and accidents at work that took place in Salvador city in the 1930 s and 1940 s. Having as its main source the compensation processes, we sought to build up the employee's profile and to know the accidents and their consequences. A stage for controversies and disputes, indemnity actions allowed observing different aspects of the working class.

Keywords: diseases; accidents; work.

Na tarde do dia 8 de dezembro de 1935, um acontecimento ocorrido no cais do porto de Salvador ganhou repercussão entre os trabalhadores da Companhia Cessionária das Docas da Bahia. O carregador Perciliano Oliveira, 29 anos, brasileiro, solteiro, ao descarregar um navio inglês, recebeu no tórax a pancada de uma lingada, sendo acometido por uma hemoptise, isto é, eliminação de sangue das vias aéreas por via oral. Ele foi socorrido por seus colegas e levado para atendimento no serviço médico da Sul América, empresa seguradora da companhia, tendo ficado aos cuidados do médico Armando Costa.

* Professora adjunta da Universidade do Estado da Bahia (UNEB). Doutora em História pela Universidade Federal de Pernambuco (UFPE). E-mail: elisa.lemos@uol.com.br. 
Perciliano ficou afastado do trabalho até o final do mês de dezembro do mesmo ano, ocasião em que, tendo alta, foi orientado a retornar às atividades. Menos de três meses depois, no dia 21 de março de 1936, voltou a "vomitar sangue", quando levantava um grande bloco de manganês. Dessa vez, em plena madrugada, foi levado por seus colegas para a residência do médico que o havia assistido anteriormente. A partir dessa data, foi submetido mais uma vez a tratamento, ficando afastado até fevereiro de 1937, quando então teve alta em caráter definitivo.

Embora otrabalhadorseconsiderasse completamenteincapacitado, o médico da seguradora alegava nada mais poder fazer, pois Perciliano era portador de uma tuberculose pulmonar, doença, segundo informava, pré-existente ao acidente. Ele deveria buscar amparo no seu Instituto de Aposentadoria e Pensão, estando a Sul América, a partir daquele momento, descomprometida com o tratamento. Não se conformando com o encaminhamento do médico, Perciliano deu entrada na Justiça baiana, no ano de 1937, num processo de indenização, buscando relacionar a tuberculose de que era portador ao trabalho que desenvolvia como carregador.' Segundo informava, antes de receber a pancada no peito gozava da mais perfeita saúde, nunca tendo faltado ao trabalho um dia sequer, desde que foi contratado pela Cia. Cessionária das Docas, em 1928.

Quatro testemunhas foram intimadas a comparecer à audiência e todas, colegas de trabalho do acidentado, confirmaram sua versão. Elas não tinham dúvida da relação entre a tuberculose e o trabalho. Dando andamento ao processo, foi solicitado um exame de sanidade física, procedimento obrigatório em ações dessa natureza. Os peritos chegaram à conclusão que o estado de saúde de Perciliano era precário. Para eles, a tuberculose de que era portador, tinha relação com o acidente sofrido. O carregador teria uma incapacidade total e permanente, que o impedia de retornar ao trabalho e que provavelmente, Ihe eliminaria "do mundo dos vivos". ${ }^{2}$ Em função da complexidade do caso, além da perícia geral, foi solicitado o parecer de um tisiologista, médico especialista em tuberculose, cujo resultado confirmou a conclusão a que chegaram os peritos. A tuberculose apresentada por Perciliano tinha relação com o trabalho.

Diante das considerações feitas nos depoimentos das testemunhas e nos pareceres dos peritos e do especialista, a ação foi julgada procedente, sendo a empresa obrigada ao pagamento de uma indenização. O caráter litigioso do processo levou-o a ser concluído no final de 1939.3 Um ano depois de finalizada a ação, outro processo de indenização por tuberculose foi aberto contra a Cia. Cessionária das Docas. Dessa vez era o guindasteiro Fernando Evangelista de Jesus, 28 anos. Não teve, no entanto, a mesma "sorte" que Perciliano, morrendo antes de ter seus direitos assegurados. ${ }^{4}$

As ações requeridas por Perciliano Oliveira e por Fernando de Jesus não foram casos isolados. Em minha dissertação de mestrado, defendida em 1998, analisei 1.254 processos de indenização por acidentes e doenças do trabalho, relativos aos anos de 1930 a 1945, em Salvador. Trinta e sete deles ocorreram na Companhia Cessionária das Docas da Bahia. ${ }^{5}$ Em termos quantitativos, essa amostra de 1.254 processos revelou que a Companhia Linha Circular de Carris da Bahia, prestadora dos serviços

1 Arquivo Público do Estado da Bahia (APEB), Seção Judiciária, Acidente de Trabalho. Estante 66, caixa 66, doc. 01.

2 APEB, Seção Judiciária, Acidente de Trabalho. Estante 66, caixa 66, doc. 01, f. 134.

3 APEB, Seção Judiciária, Acidente de Trabalho. Estante 66, caixa 66, doc. 01, f. 194.

4 APEB, Seção Judiciária, Acidente de Trabalho. Estante 68, caixa 143, doc. 03.

5 SILVA, Maria Elisa Lemos Nunes da. "Entre Trilhos, Andaimes e Cilindros: acidentes de trabalho em Salvador (1934-1944)" (Dissertação de Mestrado. Universidade Federal da Bahia, Salvador, 1998). 
de bondes, elevadores e planos inclinados, foi a empresa que ao longo do período estudado apresentou o maior número de acidentes (80 casos), seguida pela Panair do Brasil, responsável pelo serviço de transporte aéreo (64 casos) e pela Companhia Empório Industrial do Norte, empresa têxtil (44 casos). A Companhia Cessionária das Docas, voltada para a exploração do porto de Salvador, foi, portanto, o quarto estabelecimento em número de doenças e acidentes de trabalho. ${ }^{6}$

Os trabalhadores do porto tinham experiência organizativa. José Raimundo Fontes, ao estudar o movimento grevista na Bahia de 1888 a 1930, encontrou uma importante greve iniciada em 16 de março de 1891, entre os estivadores de diferentes agências localizadas no porto de Salvador. Os grevistas reivindicavam um aumento salarial em torno de 100\%.7 Aldrin Castellucci, em trabalho no qual aborda a greve geral ocorrida em Salvador em 1919, identifica nesse período cerca de oito organizações operárias atuantes entre os trabalhadores do complexo portuário. ${ }^{8}$ A participação deles na greve de 1919 foi expressiva.

Desde 1912, os estivadores estavam organizados em torno de uma associação profissional, sucursal da Sociedade União dos Operários Estivadores do Rio de Janeiro. ${ }^{9}$ Maria Cecília Velasco e Cruz, em estudo sobre a formação do sindicalismo estivador no Brasil, considera que o modelo de sindicato e a dinâmica organizacional de solidariedade e conflito dos estivadores cariocas se espalharam pelo país. Em 1925, a União dos Operários Estivadores (UOE) já tinha sucursais em diversos portos do Brasil dirigidas por trabalhadores indicados pela matriz do Rio de Janeiro. ${ }^{10}$ No que diz respeito aos carregadores, eles fundaram a Sociedade Civil União Geral dos Carregadores da Bahia no mesmo ano em que os estivadores fundaram a sua associação. ${ }^{11}$

Certamente, a tradição de luta dos trabalhadores do porto influenciava a sua capacidade de perceber as precárias condições de trabalho a que estavam submetidos. Perciliano, inclusive, era associado ao Sindicato dos Carregadores do Porto da Bahia. ${ }^{12}$ Os operários trabalhavam também durante a madrugada, expostos ao vento, à chuva e às mudanças bruscas de temperatura. Nos processos de indenização acima referidos, as testemunhas ouvidas tinham consciência que suas atividades profissionais eram danosas à saúde. Segundo o carregador Evaristo Alcântara Silva, ouvido no processo de indenização de Perciliano Oliveira, antes do acidente o trabalhador gozava de saúde. ${ }^{13}$ Para os guindasteiros Florêncio Manoel do Espírito Santo e Anísio Andrade de Jesus, testemunhas de defesa no processo de Fernando de Jesus, mencionado anteriormente, a tuberculose tinha sido adquirida no trabalho em função das condições especiais em que o mesmo era realizado. Os trabalhadores eram obrigados a trabalhar dia e noite, inclusive nas madrugadas, sujeitos a mudanças na temperatura ambiente. ${ }^{14}$

De todo modo, a instauração de ações de indenização por acidentes e doenças do trabalho foi uma possibilidade intensificada com o Decreto $n^{\circ} 3.724$, de 15 de janeiro de 1919, o primeiro a tratar do assunto no Brasil. Fruto de debates

6 SILVA. "Entre Trilhos Andaimes e Cilindros", p. 158.

7 FONTES, José Raimundo. “Manifestações Operárias na Bahia: o movimento grevista 1888-1930". (Dissertação de Mestrado Universidade Federal da Bahia, Salvador, 1982).

8 CASTELLUCCI, Aldrin Armstrong Silva. Industriais e operários baianos numa conjuntura de crise (1914-1921). Salvador: FIEB, 2014, p. 165.

9 CASTELLUCCI. Industriais e operários baianos numa conjuntura de crise (1914-1921), p. 165.

10 VELASCO E CRUZ, Maria Cecília. "Solidariedade X rivalidade: a formação do sindicalismo estivador brasileiro". História Unisinos (Dossiê Trabalho e Movimento Operário), 2002, vol. 6, n. 6, p. 29-62.

11 CASTELLUCCI, Industriais e operários baianos numa conjuntura de crise (1914-1921), p. 165.

12 APEB, Seção Judiciária, Acidente de Trabalho. Estante 66, caixa 66, doc. 01, f. 3.

13 APEB, Seção Judiciária, Acidentes de Trabalho. Estante 66, caixa 66, doc. 01, f. 54.

14 APEB, Seção Judiciária, Acidente de Trabalho. Estante 68, caixa 143, doc. 03, f. 5-6. 
no meio empresarial e operário, a legislação era apenas parte de uma discussão mais ampla sobre a constituição de uma legislação social e trabalhista no país. ${ }^{15}$

À lei de acidente de trabalho vieram juntar-se, em 1923, o projeto que aprovou as Caixas de Aposentadoria e Pensões (CAPs) para os ferroviários ${ }^{16}$ e o projeto que criou o Conselho Nacional do Trabalho (CNT). Em 1926, foram aprovadas a lei de férias para os comerciários e os operários industriais, e o Código de Menores. ${ }^{17} \mathrm{~A}$ simples previsão em lei, no entanto, não garantia o pagamento da indenização. De um lado, estava o trabalhador requerendo seus direitos e, de outro, o patrão tentando de todas as formas se eximir da responsabilidade e buscando muitas vezes desvincular o episódio do trabalho. Muitos empregadores só chegavam a cumpri-la mediante pressão.

No âmbito deste artigo, as ações movidas por Perciliano e Fernando foram tomadas como ponto de partida para abordarmos as discussões em torno da relação entre doença, acidente e trabalho, em Salvador, bem como da possibilidade de estabelecimento do nexo entre tuberculose e trabalho.

\section{Doenças e acidentes de trabalho em Salvador: algumas reflexões iniciais}

Os acidentes e as doenças do trabalho são historicamente um sério problema social. Eles estão relacionados às condições nas quais ocorrem os processos de trabalho e são intensificados nas sociedades industrializadas. No Brasil, eles foram abordados, principalmente, por estudiosos das áreas de sociologia e de saúde, embora o tema também tenha sido objeto de atenção de pesquisadores de outros campos de atuação, entre os quais o da História. ${ }^{18}$

Claudio Batalha, em artigo no qual empreende um balanço sobre a História do Trabalho no Brasil, considera que os avanços foram significativos desde o final dos anos de 1990. Houve aumento no volume e na qualidade das pesquisas, ampliação de recortes geográficos e abertura de novas abordagens, enfoques e temas. ${ }^{19}$ No que diz respeito a doenças e a acidentes de trabalho, apesar da temática ter sido visitada por historiadores, a produção ainda é incipiente. Um dos desafios a serem enfrentados

15 GOMES, Ângela de Castro. Burguesia e Trabalho: política e legislação social no Brasil 1917-1937. Rio de Janeiro: Editora Campus, 1979; MUNAKATA, Kazumi. A Legislação Trabalhista no Brasil. 2. ed. São Paulo: Brasiliense, 1984; TEIXEIRA, Palmira Petratti. A Fábrica do Sonho: trajetória do industrial Jorge Street. Rio de Janeiro: Paz e Terra, 1990.

16 Ver a este respeito: OLIVEIRA, Jaime de Araújo e Sônia M. Fleury Teixeira. (IM) Previdência Social: 60 anos de história da Previdência Social no Brasil. Petrópolis: Vozes, 1986; POSSAS, Cristina. Saúde e Trabalho: a crise da Previdência Social. 2. Edição. São Paulo: HUCITEC, 1989.

17 GOMES. Burguesia e trabalho, p. 181.

18 Na década de 1980, Esmeralda Blanco Bolsonaro de Moura abordou a questão dos acidentes de trabalho ocorridos no setor secundário em São Paulo, de 1890-1919. BOLSONARO DE MOURA, Esmeralda Blanco. "O Acidente de Trabalho em São Paulo, 1890-1919." (Tese de Doutorado. Universidade de São Paulo. 1984). Na década de 1990, Newton Augusto Cardoso de Oliveira estudou os acidentes de trabalho ocorridos na indústria têxtil do Rio de Janeiro, durante o Estado Novo, Anna Beatriz de Sá Almeida abordou as doenças de trabalho no Brasil, privilegiando a relação entre tuberculose e trabalho e Maria Elisa Lemos Nunes da Silva estudou acidentes e doenças do trabalho ocorridos em Salvador nas décadas de 1930 e 1940. Ver: OLIVEIRA, Newton Cardoso de. "A Economia do Sinistro: contribuição ao estudo dos acidentes de trabalho na indústria têxtil durante o Estado Novo, 1937-1945”. (Dissertação de Mestrado. Universidade Federal Fluminense, Rio de Janeiro, 1993); ALMEIDA, Anna Beatriz de Sá. "De Moléstia do Trabalho a Doença Profissional: contribuição ao estudo das doenças do trabalho no Brasil". (Dissertação de Mestrado. Universidade Federal Fluminense, Rio de Janeiro, 1994).

19 BATALHA, Claudio Henrique de Moraes. "Os desafios atuais da História do Trabalho". Anos 90, v. 13, n. 23/24, p. 87-104, jan./dez. 2006. 
consiste na realização de estudos voltados para diferentes espaços territoriais, possibilitando análises comparativas, envolvendo diferentes ramos de atividades.

Nas primeiras décadas do século $\mathrm{XX}$, as atividades comerciais e portuárias ainda tinham grande importância para Salvador. O comércio de importação e exportação só tinha peso inferior ao do Rio de Janeiro e de Santos. ${ }^{20}$ A despeito disso, de acordo com os cálculos de Aldrin Castellucci, em 1920 a indústria empregava 45.653 trabalhadores, $16,1 \%$ de seus 283.422 habitantes. Ainda segundo este autor, se agregarmos os trabalhadores marítimos, fluviais e terrestres, teremos uma classe trabalhadora composta por 54.635 pessoas, 19,3\% da população da capital baiana, sem dúvida uma força social considerável. ${ }^{21}$ As condições de trabalho eram precárias. Os trabalhadores das fábricas, oficinas e estabelecimentos comerciais eram submetidos a longas jornadas, em ambientes mal iluminados e pouco ventilados. Doenças e acidentes eram frequentes. A repercussão desses eventos extrapolou o espaço específico do trabalho, sendo inclusive tema de publicações operárias e pauta de movimentos grevistas.

José Raimundo Fontes encontrou 43 greves ocorridas em Salvador de 1919 a 1930. Das 14 categorias identificadas, os trabalhadores de transportes urbanos foram os que fizeram o maior número de paralisações..$^{22} \mathrm{~A}$ maioria delas tinha reivindicações salariais. Algumas almejaram melhorias das condições de trabalho, com redução da jornada de trabalho e cerca de dez greves trataram de questões de solidariedade de classe (readmissão de companheiros demitidos). ${ }^{23}$ No entanto, a salubridade dos ambientes de trabalho também esteve presente. Castellucci considera que o movimento operário desse período, nas suas reivindicações, agregou problemas mais ligados ao mundo do trabalho como, por exemplo, aqueles relacionados à jornada, à mão de obra infantil e feminina e à salubridade. ${ }^{24}$

Segundo Consuelo Novais Sampaio, na greve dos trabalhadores da Cia. Linha Circular de Carris da Bahia, ocorrida em Salvador em 1934, os trabalhadores mostraram consciência da dura realidade a que estavam submetidos, trabalhando desprotegidos nas linhas de alta tensão, intoxicando-se nas valas das oficinas, e vítimas de muitos acidentes de trabalho. ${ }^{25}$

\section{Doenças, acidentes de trabalho e seus desdobramentos}

Mas afinal, quem era o trabalhador que se acidentava em Salvador nas décadas de 1930 e 1940? Quais as doenças e os acidentes que ocorriam? Que desdobramentos tinham esses eventos danosos à saúde do trabalhador? Para responder a esses questionamentos me reportarei à amostra construída com os 1.254 processos de indenização por doenças e acidentes de trabalho acontecidos no período em questão.

Nas últimas décadas no Brasil, a documentação judicial tem sido considerada uma importante fonte de pesquisa para historiadores e cientistas sociais. Por meio

20 SANTOS, Mário Augusto Silva. “Crescimento urbano e habitação em Salvador”. RUA, Revista de Arquitetura e Urbanismo n. 4/5, p. 20, jun./dez. 1990.

21 CASTELLUCCI. Industriais e operários baianos numa conjuntura de crise (1914-1921), p. 45-56.

22 FONTES. "Manifestações operárias na Bahia", p. 68.

23 FONTES. "Manifestações operárias na Bahia", p. 239.

24 CASTELLUCCI. Industriais e operários baianos numa conjuntura de crise (1914-1921), p. 150.

25 SAMPAIO, Consuelo Novais. "Movimentos Sociais na Bahia de 1930: Condição de Vida do Operariado". Universitas (29), p. 103-104, jan./abr. 1982. 
dela, é possível observar aspectos do cotidiano e da luta por direitos empreendida por homens e mulheres, livres e escravos, bem como as concepções acerca das leis, dos direitos e da justiça. ${ }^{26}$ Os processos de indenização por doenças e acidentes de trabalho eram julgados por juntas cíveis ou pelas juntas de acidentes de trabalho, situação que se manteve inalterada mesmo depois de ter sido criada a Justiça do Trabalho. ${ }^{27} \mathrm{Na}$ Bahia, atendendo ao disposto no Decreto $\mathrm{n}^{\circ} 24.637$, de $1^{\circ}$ de julho de 1934, foi criado, em novembro de 1935, o Cartório dos Feitos de Acidentes de Trabalho, sendo transferidas para a Vara Cível as ações que antes ficavam na Vara da Fazenda. ${ }^{28} \mathrm{O}$ Cartório de Acidentes de Trabalho seria servido por um escrivão que deveria participar dos processos de indenização, organizar semestralmente as estatísticas e promover a guarda do arquivo. ${ }^{29}$ Teria também presença constante nos processos o Curador de Acidentes de Trabalho. ${ }^{30} \mathrm{~A}$ ele competia, entre outras coisas, acompanhar os processos relativos à indenização e promover a revisão da indenização, interpondo recursos legais nos casos em que o trabalhador ou seus herdeiros se sentissem prejudicados com a sentença. ${ }^{31}$

É importante ainda entender que os processos de indenização apresentam uma visão direcionada sobre o acidente. Os interrogados (acidentados, testemunhas e empre-gador), respondiam a perguntas previamente formuladas com base na legislação e transcritas pelos escrivães. Não havia a fala direta e livre do trabalhador sobre o ocorrido.

De todo modo, essa documentação apresenta elementos para estabelecer um perfil do trabalhador no que diz respeito ao sexo, à idade, à ocupação, ao empregador, bem como possibilita identificar as causas dos acidentes, as partes do corpo atingidas, as incapacidades geradas ou mesmo os casos de morte. Permite, ainda, de certa forma, observar as condições de trabalho e os discursos construídos sobre os acidentados. Para as testemunhas, seus colegas de trabalho, eles eram "homens sérios", cumpridores dos deveres e tinham "hábitos saudáveis de vida”. Já o empregador, muitas vezes, considerava-os negligentes, imprudentes ou mesmo mentirosos.

Os processos de indenização tinham objetivos compensatórios, visando reparar monetariamente um acidente já consumado. Embora fossem interpretados à luz da legislação definidora do que seria um acidente ou uma doença do trabalho, eles eram passíveis de controvérsia. Segundo o Decreto $\mathrm{n}^{\circ} 3.724$, de 15 de janeiro de 1919, o acidente de trabalho era considerado um acontecimento "produzido por uma causa súbita, violenta, externa e involuntária no exercício do trabalho, determinando lesões corporais, ou perturbações funcionais" que constituíssem a causa única da morte ou perda total, ou parcial, permanente ou temporária da capacidade para o trabalho..32 Esse decreto equiparava as doenças do trabalho ao acidente para efeito de indenização, mas considerava como moléstias do trabalho apenas as contraídas exclusivamente no exercício do trabalho. Tratava-se de uma definição restritiva. E ainda havia o pagamento de indenização, ao invés do pagamento de pensão. Esse resultado foi fruto de interferência do Centro Industrial do Brasil (CIB). Tinha também

26 GOMES, Ângela de Castro; SILVA, Fernando Teixeira (Org.). A Justiça do Trabalho e sua história: os direitos dos trabalhadores no Brasil. Campinas, SP: Editora da Unicamp, 2013, p. 26.

27 A Justiça do Trabalho foi criada pela Constituição de 1934, mas só começou a funcionar em $1^{\circ}$ de maio de 1941. GOMES; SILVA (Org.) A Justiça do Trabalho e sua história, p. 20.

28 BAHIA, Imprensa Oficial. Lei no 8, de 14 de novembro de 1935, p. 6.

29 BAHIA, Imprensa Oficial. Lei $n^{\circ} 8$, de 14 de novembro de 1935, p. 6.

30 BAHIA, Imprensa Oficial. Lei $n^{\circ}$ 151, de 12 de dezembro de 1936.

31 BAHIA, Imprensa Oficial. Lei $n^{\circ} 151$, de 12 de dezembro de 1936, p. 23.

32 BRASIL, Atos do Poder Legislativo. Decreto n 3.724, de 15.01.1919, p. 166. 
outras limitações, a exemplo da exclusão dos acidentes de trajeto e aqueles que teriam sido causados por "força maior". ${ }^{33}$

Mas a primeira lei substituiu a "teoria da culpa" pela teoria do "risco profissional". ${ }^{34}$ Anteriormente, caso um trabalhador viesse a se acidentar, poderia entrar na justiça com um pedido de indenização, mas tinha que provar que não teve culpa. Esse elemento deixa transparecer a dificuldade que deveria ser o recebimento de indenizações. Vale lembrar que o princípio do "risco profissional" responsabilizava o patrão não por uma falta "que merecesse castigo", mas por uma reparação decorrente de razões meramente profissionais, pois a ocorrência de acidentes não era devida à negligência patronal, mas, ao risco profissional inerente a qualquer trabalho. ${ }^{35}$

Em 1934, a legislação de acidente de trabalho foi modificada. Tratava-se de um contexto de centralização política e intervenção estatal intensificados com a chamada Revolução de 1930. Uma das primeiras medidas do Governo Provisório foi a criação do Ministério do Trabalho, Indústria e Comércio. Este seria "o aparelho estatal munido de instrumentos teóricos, técnicos, racionais [...] capazes de operar a redefinição do lugar das leis trabalhistas." ${ }^{36}$ Ele foi o palco central de discussão e formulação das políticas relativas à saúde e ao trabalho. Dentre os vários órgãos a ele ligados estavam o Conselho Nacional do Trabalho (CNT), criado em 1923, e o Departamento Nacional do Trabalho (DNT). O primeiro manteve a mesma estrutura anterior, ficando responsável pelo controle do sistema previdenciário. ${ }^{37}$ O DNT, criado em 1931 e regulamentado em 1934, encarregou-se das questões relativas à execução, à fiscalização e ao cumprimento da legislação trabalhista, bem como organizou Inspetorias Regionais, verdadeiros embriões das atuais Delegacias Regionais do Trabalho - DRT. ${ }^{38}$

Um dos setores-chave do Ministério no sentido de conquistar espaços junto ao movimento sindical foi o de Fiscalização das Leis Sociais que, inicialmente, ficou subordinado ao Conselho Nacional do Trabalho passando, posteriormente, ao Departamento Nacional do Trabalho quando foram criadas as Inspetorias do Trabalho. ${ }^{39}$ Mas o principal objetivo político do Ministério do Trabalho era eliminar qualquer possibilidade de conflito entre capital e trabalho. A partir de 1930, houve certa convergência entre o discurso patronal e governamental, pois ambos diziam que a legislação social, atendendo aos reclamos dos trabalhadores podia garantir a "paz social" e assim um desenvolvimento econômico mais seguro dos "negócios nas cidades". ${ }^{40}$ Nesse cenário, o conceito de acidente foi ampliado, passando a ser considerada toda lesão corporal, perturbação funcional ou doença produzida pelo exercício do trabalho, ou em consequência dele, que determinasse "a morte, ou a suspensão, ou a limitação, permanente ou temporária, total ou parcial da capacidade para o trabalho." "11 Da mesma forma, foi ampliado o conceito de doença ocupacional, que passou a ser considerada, para efeito de indenização, além das

33 Acidente de trajeto é aquele que ocorre com o trabalhador durante o deslocamento casa-trabalho e viceversa.

34 Araújo Castro, na introdução à primeira edição do seu livro "Acidentes do Trabalho", enaltece a lei de acidentes, colocando-a como o primeiro passo decisivo para a solução das grandes questões sociais, igualando-se às nações civilizadas. Ver: CASTRO, Araújo. Acidentes do Trabalho. $4^{a}$. edição. Rio de janeiro: Livraria Editora Freitas Bastos, 1935, p. 5.

35 GOMES. Burguesia e Trabalho, p. 173; MUNAKATA. A Legislação trabalhista no Brasil, p. 34-35.

36 MUNAKATA. A Legislação trabalhista no Brasil, p. 66.

37 MUNAKATA. A Legislação trabalhista no Brasil, p. 72.

38 MUNAKATA. A Legislação trabalhista no Brasil, p. 75-80.

39 GOMES, Ângela de Castro. A Invenção do Trabalhismo. 2a . edição. Rio de Janeiro: Relume Dumará, 1994, p. 149.

40 GOMES. Burguesia e Trabalho, p. 205.

41 BRASIL, Arquivo Judiciário. Decreto 24.637 de 10 de julho de 1934, p. 317. 
inerentes a determinados ramos de atividades, as resultantes do exercício do trabalho ou das condições em que ele era realizado.

Nova mudança ocorreu em 1944 com o Decreto $n^{\circ} 7.036$, segundo o qual seria acidente de trabalho o que ocorresse pelo exercício do trabalho provocando "direta ou indiretamente" lesão corporal, perturbação funcional, ou doença, que determinasse "a morte, a perda total ou parcial, permanente ou temporária da capacidade para o trabalho". ${ }^{22}$ Foi também estabelecido o que se chamou de "concausa", possibilitando caracterizar o acidente a partir de uma relação de causa e efeito, não necessitando que ele fosse a única causa da morte ou da incapacidade. Assim, a definição de acidente e de doença do trabalho, palco de controvérsias e de disputas políticas, embora tenha se modificado, continuou excludente, permanecendo sem direito a indenização os trabalhadores vítimas de acidentes de trajeto e os empregados domésticos.

O patronato foi favorável à formação de seguradoras que funcionariam no ramo de acidentes de trabalho. Ao estabelecer contratos com as companhias e seus empregados, transferia os encaminhamentos para elas. Aos empregadores caberia apenas notificar o fato à autoridade competente. Em assembléia geral ocorrida em outubro de 1919, a diretoria do CIB ficou encarregada de promover a incorporação de uma companhia de seguros. Foi, então, que surgiu, em 1920, a Companhia Segurança Industrial sob a presidência de Costa Pinto, secretário do CIB. ${ }^{43}$ Assim, o empresariado, além de ter conseguido a aprovação do pagamento de indenização, tirou da lei vantagens econômicas com a constituição de companhias seguradoras. A grande prestadora dos seguros, no caso de acidentes de trabalho, foram as empresas privadas, mesmo que o seguro pudesse ser feito por outras organizações, a exemplo das caixas, das cooperativas e dos institutos.

Em Salvador, no início dos anos de 1930, praticamente só funcionavam duas seguradoras no ramo dos acidentes de trabalho, a Sul América e a Companhia Segurança Industrial. Esta última, fundada em 1920 no Rio de Janeiro, foi a mais importante empresa nesse ramo na capital da Bahia.

Tabela 1

Relação das Companhias Seguradoras (Salvador, 1930-1945).

\begin{tabular}{c|c}
\hline SEGURADORAS & FREQUENCIA \\
\hline Cia. Segurança Industrial & 461 \\
\hline Sul América & 190 \\
\hline Equitativa & 87 \\
\hline Metrópole & 59 \\
\hline Cia. Lloyd Industrial Sul Americana & 52 \\
\hline Seguradora indústria e Comércio & 35 \\
\hline Brasil Cia. de Seguros Gerais & 22 \\
\hline A Fortaleza & 15 \\
\hline Cia. Internacional de Seguros & 15 \\
\hline Meridional & 12 \\
\hline Atlântica & 12 \\
\hline Oia. de Seguros Minas Brasil & 10 \\
\hline TOTALas & 9 \\
\hline
\end{tabular}

Fonte: Arquivo Público do Estado da Bahia (APEB), Seção Judiciária, processos de indenização, anos indicados.

42 BRASIL, Legislação Federal. Decreto 7.036 de 10 de novembro de 1944, p. 377.

43 TEIXEIRA. A fábrica do sonho, p. 112. 
Como pode ser visto na Tabela 1, ao longo do período estudado há aumento significativo do número de companhias que atuaram no ramo de acidentes de trabalho em Salvador. Isso não ocorreu por acaso. Se houve tanto interesse foi porque ele trazia retorno certo para os seus investidores. No entanto, nem todas as empresas em Salvador estabeleceram contrato com seguradoras. Quando isso acontecia e o empregador alegava não ter condições de pagar, o desdobramento do processo poderia ser desfavorável ao trabalhador. Foi o que ocorreu, por exemplo, com Virgílio Euclides dos Santos, 24 anos, solteiro, brasileiro, padeiro da Padaria Comercial, de propriedade de José Amoedo. Em 12 de agosto de 1933, ele teve parte do dedo indicador direito esmagado pela hélice de uma batedeira. ${ }^{44} \mathrm{As}$ testemunhas arroladas confirmaram a declaração do trabalhador. Acidentes dessa natureza eram frequentes nas padarias. Embora o empregador reconhecesse sua responsabilidade, alegava não ter recursos para pagar a indenização, pois o estabelecimento de sua propriedade estava em liquidação judicial, requerida pelos seus credores hipotecários. Apesar de ter sido julgado favorável ao empregado, inclusive com a indicação de separação de bens do empregador para a garantia do crédito ao acidentado, o processo não foi concluído e o trabalhador acabou sem receber a indenização.

Encontrei 147 processos de indenização por acidentes de trabalho ocorridos em padarias, num total de 159 do ramo de alimentos. Quanto aos acidentes sucedidos em outros setores, na construção civil houve 135 casos, seguidos pelo têxtil, com 98 ocorrências, e por 88 em transportes urbanos, dos quais 80 foram com trabalhadores do serviço de bondes da Companhia Linha Circular de Carris da Bahia.

A expressividade de acidentes na construção civil não é uma especificidade de Salvador. Newton Cardoso de Oliveira, ao estudar os acidentes de trabalho durante o Estado Novo, no Rio de Janeiro, chamou atenção para a primazia das ocorrências nesse ramo de atividade na antiga capital da República..$^{45} \mathrm{Em}$ meu estudo, constatei que, dos 135 processos referentes à construção civil, os acidentados exerciam as seguintes ocupações: pedreiro (48), servente de pedreiro (44), carpinteiro/ marceneiro (22). Foram encontrados também cinco pintores, cinco estucadores, dois mecânicos e dois motoristas. Em outras ocupações como, por exemplo, ferreiro, vigilante, forneiro, encarregado de obras e polidor de ladrilhos, houve um caso para cada uma delas.

Vale ressaltar que a grande ocorrência de acidentes de trabalho na construção civil não era uma característica do período em estudo. Pesquisas que abordaram recortes temporais mais recentes chamaram a atenção para a incidência dos acidentes nesse ramo, inclusive daqueles com morte. ${ }^{46}$ Marcelino Elias do Nascimento, 36 anos, carpinteiro, morreu após cair de um andaime de uma obra que estava sendo realizada pela firma Leibnitz e Adelson, no edifício do antigo Correio Geral. Na ação de indenização, requerida pela beneficiária e esposa da vítima, ficou estabelecido que o trabalhador morreu de "hemorragia interna e externa por fratura da base do crânio e seção dos vasos intercostais", em consequência do acidente de trabalho sofrido em dezembro de 1942.0 processo foi concluído em 12 de dezembro de 1946, quando a Seguradora Indústria e Comércio S. A. pagou a indenização.

44 APEB, Seção Judiciária. Estante 67, caixa 82, doc. 10, f. 17.

45 OLIVEIRA. "A economia do sinistro", p. 184.

46 RÊGO, Marco Antônio Vasconcelos. "Acidentes e Doenças do Trabalho no Estado da Bahia, 1970-1992". Revista Brasileira de Saúde Ocupacional, v. 22, p. 21-23, 1994; NETO, Aníbal Muniz et al. "Acidentes fatais do trabalho na Região Metropolitana de Salvador, 1978-1986”. Revista Baiana de Saúde Pública, v. 19, p. 19-31, jun./dez. 1988. 
Foram encontrados 84 processos de indenização relativos a acidentes com morte. A principal parte do corpo atingida nos acidentes fatais foi a cabeça, com $32,6 \%$ dos casos identificados. Logo em seguida estavam o tórax e o abdome, ambos com $17,4 \%$ cada. Pé, perna e coluna estiveram em quarto lugar e os acidentes que atingiram todo o corpo, em terceiro.

\section{Tabela 2}

Causa dos Acidentes com morte (Salvador, 1930-1945).

\begin{tabular}{c|c|c}
\hline CAUSA & FREQUENCIA & PERCENTUAL \\
\hline Veículo/bonde & 12 & $20,3 \%$ \\
\hline Choque elétrico & 11 & $18,6 \%$ \\
\hline Queda em altura & 7 & $11,9 \%$ \\
\hline Desabamento & 6 & $10,2 \%$ \\
\hline Pancada/traumatismo & 4 & $6,8 \%$ \\
\hline Queimadura & 3 & $5,1 \%$ \\
\hline Afogamento & 3 & $5,1 \%$ \\
\hline Carregamento de peso & 2 & $3,4 \%$ \\
\hline Pedra & 2 & $3,4 \%$ \\
\hline Instrumento cortante/perfurante & 1 & $1,7 \%$ \\
\hline Guindaste & 1 & $1,7 \%$ \\
\hline Máquina sem especificação & 1 & $1,7 \%$ \\
\hline Alvarenga & 1 & $1,7 \%$ \\
\hline Carretel de máquina & 1 & $1,7 \%$ \\
\hline Lata de massa & 1 & $1,7 \%$ \\
\hline Explosão & 1 & $1,7 \%$ \\
\hline Hérnia estrangulada & 1 & $1,7 \%$ \\
\hline Verga & 1 & $1,7 \%$ \\
\hline TOTAL & 59 & $100 \%$ \\
\hline
\end{tabular}

Fonte: APEB, Seção Judiciária, processos de indenização de Acidente de Trabalho, anos indicados.

De acordo com a Tabela 2, do total de processos de indenização relativos a acidentes com morte que tiveram a causa indicada, o veículo foi a mais frequente. Em segundo lugar estava o choque elétrico, que também foi uma importante causa em relação aos acidentes de um modo geral. Marcelino foi, portanto, um dos sete casos de acidente de trabalho com morte cuja causa foi "queda em altura".

Entre os acidentes fatais, apenas um ocorreu com mulher. Ela chamava-se Angélica Cândida Vilas Boas e trabalhava numa fábrica de calçados. Foi vítima de um desabamento em 1941, tendo morrido de hemorragia interna. O processo foi concluído em fevereiro de 1943 , ocasião em que seu filho recebeu a indenização. ${ }^{47}$ Estatísticas de acidentes fatais, referentes aos anos de 1938 e 1940, revelaram a ocorrência de oito acidentes em cada ano. Todos ocorridos com homens. Portanto a ocorrência de acidentes fatais com mulheres era pequena..$^{48} \mathrm{~A}$ questão da gravidade dos acidentes e sua diferenciação em relação ao sexo pode ser percebida, também, nos acidentes com incapacidade total e permanente, a mais grave delas. Dos 43 casos identificados, todos ocorreram com homens. Isso se prendia às ideologias de gênero que respondiam pela divisão sexual do trabalho.

47 APEB, Seção Judiciária. Acidente de Trabalho, estante 66, caixa 40, doc. 50.

48 Arquivo Público do Estado da Bahia (APEB). Demonstrativo dos acidentes de trabalho que ocasionaram mortes, $1^{\circ}$ semestre 1938; Demonstrativo dos acidentes de trabalho que causaram morte, 1940 . Seção Republicana. Secretaria de Segurança Pública do Estado da Bahia. Seção de Estatística e Publicidade. Caixa 33, pacote 03. 
Mas, em termos quantitativos gerais, entre os 1.254 processos estudados, o número de acidentes ocorridos com homens representou $96 \%$ da amostra e com mulheres $4 \%$ ( 50 casos).

Francisca Paula dos Santos, 21 anos, tecelã da Cia. Empório Industrial do Norte, recebeu uma forte pancada no seio direito, em 30 de dezembro de 1937, ocasionada por uma lançadeira. Ela foi uma das 31 mulheres acidentadas do ramo têxtil, de um total de 98 acidentes que ocorreram nesse ramo. Destas, doze trabalhavam na Cia. Empório Industrial do Norte, onze na Companhia Progresso e União Fabril, e oito na Companhia Fabril dos Fiais. Ou seja, mesmo no ramo onde há uma significativa presença feminina, os acidentes com homens ainda tiveram maior frequência. ${ }^{49}$ Essa análise pode ser visualizada ao observarmos duas estatísticas de acidentes de trabalho referentes ao ano de 1938, portanto, um ano após o acidente ocorrido com Angélica Vilas Boas. Elas nos dão a incidência de acidentes com mulheres e com homens. No primeiro semestre desse ano foram notificados 2.228 acidentes, dos quais 1.995 (89,5\%) ocorreram com homens e 233 $(10,5 \%)$ com mulheres. No segundo semestre do mesmo ano foram registrados 2.839 acidentes: 2.657 (93,6\%) em homens e 182 (6,4\%) em mulheres. ${ }^{50}$ Assim, era mesmo bem menor a incidência de mulheres acidentadas, refletindo sua inserção ainda reduzida no mercado formal de trabalho.

Tabela 3

Idade dos Acidentados (Salvador, 1930-1945).

\begin{tabular}{c|c|c}
\hline IDADE & FREQUÊNCIA & PERCENTUAL \\
\hline 12 a 14 anos & 10 & $0,8 \%$ \\
\hline 15 a 17 anos & 41 & $3,3 \%$ \\
\hline 18 a 20 anos & 94 & $7,6 \%$ \\
\hline 21 a 30 anos & 521 & $42,1 \%$ \\
\hline 31 a 40 anos & 311 & $25,1 \%$ \\
\hline 41 a 50 anos & 169 & $13,7 \%$ \\
\hline 51 a 60 anos & 75 & $6,1 \%$ \\
\hline 61 a 70 anos & 15 & $1,2 \%$ \\
\hline 71 a 78 anos & 2 & $0,2 \%$ \\
\hline TOTAL* & 1.238 & $100,0 \%$ \\
\hline
\end{tabular}

* Excluídos 16 casos com informações ignoradas.

Fonte: APEB, Seção Judiciária, processos de indenização por acidentes de trabalhos, anos indicados.

Quanto à idade, a Tabela 3 mostra que $80,9 \%$ dos trabalhadores acidentados tinham entre 21 e 50 anos, faixa etária que pode ser considerada como a mais produtiva. O trabalho infantil foi largamente denunciado e duramente combatido pelo movimento operário brasileiro durante a Primeira República. Mas na Salvador dos anos de 1930 e 1940, o trabalho de crianças e jovens ainda era uma realidade presente, e as doenças e acidentes do trabalho eram recorrentes.

Valdemar Neves dos Santos, 13 anos, acidentou-se em 11 de julho de 1944, quando trabalhava na Padaria São João, de propriedade de Manoelito Vargas. Segundo o relato de Vitalina da Conceição, sua tutora, Valdemar foi designado a entregar, numa venda distante da referida padaria, um balaio contendo cerca de 650 "padas de pão". O volume, demasiadamente excessivo para ser conduzido por uma criança de estrutura física "abaixo do normal", resultou na sua

49 APEB, Seção Judiciária, Acidente de Trabalho. Estante 68, caixa 140, doc. 02.

50 APEB, Seção Republicana, Secretaria de Segurança Pública. Caixa 33, maço 03. 
completa incapacidade de "suspender qualquer peso" por menor que fosse. ${ }^{51}$ O empregador, entretanto, havia se negado a indenizá-lo, sem ter, sequer, contribuído para o tratamento de saúde do menor trabalhador. Assim, era solicitado que fosse intimado o responsável a fim de ser dado prosseguimento ao processo judicial. Em agosto de 1944, a Comissão de Assistência Judiciária indicou um advogado para requerer o benefício da justiça gratuita em favor do acidentado. O processo se arrastou por quase três anos até que em maio de 1947, o juiz de direito responsável pelo caso intimou os interessados a comparecerem à audiência, que não se realizou em função da ausência do empregador. Em maio de 1948, o processo foi arquivado, após ter sido publicado edital de convocação no Diário da Justiça.

Ainda de acordo com a Tabela 3, Valdemar foi um dos 10 acidentados que tinham entre 12 e 14 anos. Segundo o Código de Menores decretado em 1927, era proibido em todo o território nacional o trabalho do menor de 12 anos. Aos menores de 14 anos só seria permitido trabalhar aquele que tivesse completado a instrução primária. No entanto, abria exceção para os casos em que o trabalho do menor fosse indispensável à subsistência dele e de sua família. Só foram encontrados três menores sem alfabetização. O Código de Menores proibia, também, aos menores de 18 anos, "trabalhos perigosos à saúde", à vida, à moralidade, bem como os que fossem "excessivamente fatigantes" ou que "excedessem suas forças"..$^{22}$ Antes de 14 anos, segundo o artigo 103, os menores não poderiam trabalhar em manufaturas, estaleiros, minas, pedreiras, oficinas, fossem públicas ou privadas. ${ }^{53}$ Baseado nesse artigo, Carlos Alberto de Oliveira, de 12 anos, não poderia estar trabalhando como aprendiz de mecânico na Oficina Belmonte, quando teve fratura na extremidade inferior do rádio, causada por uma polia. No entanto, no processo de indenização a que deu entrada, não há referência a esse aspecto. ${ }^{54}$

Pode-se questionar se o trabalho era fiscalizado para que não excedesse a capacidade física de jovens e crianças. Nada adiantaria o local estar aparentemente dentro do previsto pela legislação se houvesse sobrecarga, como foi o caso de Valdemar Neves, referido anteriormente. Ter, por exemplo, estrutura física "abaixo do normal", devia ser bem comum em crianças de famílias proletárias submetidas a dieta alimentar abaixo das necessidades diárias para um bom desenvolvimento. Assim, esses aprendizes ficavam mutilados ou incapacitados antes mesmo de entrarem efetivamente no mercado de trabalho.

\section{As especificidades das doenças do trabalho}

As doenças do trabalho foram equiparadas aos acidentes, para efeito de indenização, desde a primeira lei de acidente de trabalho. No entanto, houve pouco registro a seu respeito em Salvador. $\mathrm{O}$ acidente era um acontecimento agudo, violento, que representava uma interrupção súbita do processo de trabalho, portanto, mais difícil de ser omitido. Mesmo assim, muitos empregadores tentavam negá-lo, necessitando que o próprio trabalhador ou seus dependentes o comunicasse à autoridade competente. Já a doença, muitas vezes, estabelecia-

51 APEB, Seção Judiciária, Acidente de Trabalho, estante 66, caixa. 69, doc. 15.

52 CHAVES, Antônio e MORAES, Walter. Código de Menores. São Paulo: Livraria e Editora Universitária de Direito Ltda. EUD, 1974, p. 97.

53 CHAVES. Código de Menores, p. 97.

54 APEB, Seção Judiciária. Acidente de Trabalho, estante 66, caixa 57, doc. 01. 
se gradativamente, sem sintomatologia inicial. Os indivíduos podiam continuar trabalhando até que ficassem incapacitados para exercer a profissão. Às vezes, nem o próprio trabalhador se dava conta de que era portador de uma doença do trabalho. Porém, a baixa notificação dos casos não pode ser explicada apenas pela dificuldade do diagnóstico, ou mesmo pela falta de conhecimento por parte dos médicos de que determinadas patologias tinham relação com o trabalho.

A identificação da relação entre doenças e trabalho é antiga. Já no final do século XVII e início do XVIII o médico italiano Bernardino Ramazzini publicou De Morbis A. Diatriba, ${ }^{55}$ obra na qual relacionava cerca de cinquenta patologias às atividades de trabalho na Itália pré-industrial. Referia-se, por exemplo, aos problemas pulmonares causados por poeira que atingiam os mineiros, ourives, alquimistas, destiladores de aguardente, oleiros, espelheiros, fundidores, estanhadores, pintores etc. ${ }^{56}$ Ramazini diagnosticava intoxicações diversas e outras doenças, como a que atingia os escribas que adquiriam lesões em função do ato contínuo de escrever.

Na capital da Bahia, a discussão da relação entre saúde e trabalho não esteve de todo ausente. ${ }^{57} \mathrm{Em} \mathrm{1900}$, Álvaro da Motta e Silva, em sua tese de doutoramento em medicina intitulada A Medicina Legal nos Acidentes de Trabalho, mostrava-se preocupado quanto ao aumento do número de acidentes do trabalho e de moléstias profissionais. No que diz respeito a essas últimas, referindo-se a Ramazzini, comentava que "sempre o exercício das artes e as profissões manuais produziu moléstias"..$^{8}$ Para Motta e Silva, o risco da doença não era imprevisto, diferentemente do acidente de trabalho. Daí porque, em sua opinião, as doenças do trabalho eram mais importantes que os acidentes, pois o risco era certo e fatal para algumas profissões. E dava alguns exemplos: as cardaduras do linho, a tecelagem, a ação de vapores de chumbo, mercúrio, arsênico, fósforo, das partículas minerais e metálicas. Lembrava que a intoxicação era "um dos mais vastos capítulos da moléstia profissional." 59

Assim, muitas doenças identificadas por Ramazzine, num determinado momento histórico italiano, como sendo causadas pelo trabalho, ainda podiam ser encontradas em Salvador nas primeiras décadas do século XX, decorrentes de ambientes e de processos de trabalho insalubres, nos quais não havia fiscalização por parte dos órgãos governamentais.

55 RAMAZZINI, Bernardino. As Doenças dos Trabalhadores. Trad. Raimundo Estrela. São Paulo: Fundacentro, 1985, p. 15. Do original "De Morbis Artificum Diatriba", editado pela primeira vez em 1700, mas que posteriormente foi sendo publicado com outros capítulos complementares até chegar à edição definitiva em 1713.

56 RAMAZZINI. As Doenças dos Trabalhadores, p. 19.

57 Encontrei quatro teses de conclusão do curso de Medicina da Faculdade de Medicina da Bahia que abordaram o tema relativo à saúde e trabalho. São elas: A Medicina Legal dos Acidentes de Trabalho, de Álvaro da Motta e Silva (1900); Considerações Hygiênicas Relativas ao Trabalho, de Climério Ribeiro Guimarães (1906); Accidentes do Trabalho, de Manoel Thaumaturgo de Miranda (1909) e Ligeiras Considerações sobre Perícia Médica nos Acidentes de Trabalho, de José Fernandes Gurjão (1920).

58 MOTTA e SILVA, Álvaro da. A Medicina Legal dos Acidentes de Trabalho. BAHIA, Lytho-Typ. e Enc. Reis \& C. 1900, p. 17.

59 MOTTA e SILVA. A Medicina Legal dos Acidentes de Trabalho, p. 19-20. 
Tabela 4

Doenças Relacionadas ao Trabalho (Salvador, 1930-1945).

\begin{tabular}{c|c|c|}
\hline DOENÇA & FREQUÊNCIA & PERCENTUAL \\
\hline Hérnia & 18 & $45,0 \%$ \\
\hline Tuberculose & 9 & $22,5 \%$ \\
\hline Perturbação nervosa & 5 & $12,5 \%$ \\
\hline Tétano & 4 & $10,0 \%$ \\
\hline Surdez & 3 & $7,5 \%$ \\
\hline Nevralgia traumática & 1 & $2,5 \%$ \\
\hline TOTAL & 40 & $100,0 \%$ \\
\hline
\end{tabular}

Fonte: APEB, Seção Judiciária, processos de indenização por acidentes de trabalho, anos indicados.

$\mathrm{Na}$ amostra de 1.254 processos de indenização, apenas 40 foram relativos a doenças relacionadas ao trabalho, como pode ser observado na Tabela 4. As doenças referidas quase sempre foram consequências de acidentes de trabalho. Até os três casos de perdas auditivas, patologia muito frequente entre os trabalhadores expostos a ruídos intensos, foram decorrentes de acidentes de trabalho. Cabe destacar os nove casos de tuberculose, pois, embora houvesse uma grande expressividade dessa doença entre os trabalhadores, não era fácil caracterizá-la como doença do trabalho. A tuberculose, uma patologia transmissível, tinha alta incidência e mortalidade em diversas cidades do Brasil e do mundo. Em Salvador, 21.711 pessoas morreram por tuberculose apenas no intervalo entre 1932 e 1946.60

Entre os médicos não existia consenso acerca da relação entre tuberculose e trabalho. Havia aqueles que buscavam atribuí-la às formas de vida dos trabalhadores, enquanto outros admitiam que as condições de trabalho poderiam causar a doença. Em 1945, a médica Dagmar Guedes, através do jornal O Momento, órgão ligado ao Partido Comunista do Brasil (PCB), denunciou a ocorrência de tuberculose entre os trabalhadores da Cia. Linha Circular de Carris da Bahia. ${ }^{61}$ Segundo essa médica, as estatísticas apresentadas pela Caixa de Aposentadoria e Pensão da empresa indicavam a incidência de tuberculose em cerca de $70 \%$ dos aposentados daquele grupo profissional. Os trabalhadores chegavam, inclusive, a reivindicar dois fardamentos por ano, alegando que ficavam sujeitos "às intempéries mal vestidos e mal agasalhados". ${ }^{62}$ Os trabalhadores da Cia. Linha Circular de Carris da Bahia constituíam a categoria dos transviários. Na empresa, havia os motorneiros, condutores, eletricistas, fiscais de bonde e os trabalhadores das oficinas de reparação. Os serviços de bondes, a cargo da Cia. Linha Circular de Carris da Bahia, eram prestados precariamente.

José Neri dos Santos, 33 anos, fiscal de bonde da Cia. Linha Circular de Carris da Bahia teve hemoptise após receber forte pancada na região toráxica, quando bateu contra uma das colunas do bonde em movimento. ${ }^{63} \mathrm{O}$ acidente ocorreu em 17 de janeiro de 1944. Imediatamente o trabalhador comunicou o acidente ao inspetor que, ao chegar ao local, "ainda viu os escarros sanguíneos". Logo em seguida foi ao escritório da companhia, onde foi expedida uma guia para a seguradora, Cia. Segurança Industrial, ficando o trabalhador em tratamento até 18

60 NUNES, Fábio de Carvalho. A mortalidade por tuberculose na cidade do Salvador. Salvador: Secretaria de Educação e Saúde, 1949, p. 23.

61 Esse periódico, criado em abril de 1945, colocava-se como "porta-voz" da classe trabalhadora. Ver: SERRA, Sônia. "O Momento: história de um jornal militante". (Dissertação de Mestrado. Universidade Federal da Bahia, Salvador, 1987).

62 O Momento, Salvador, 16 abr. 1945, p. 7.

63 APEB, Seção Judiciária, Acidente de Trabalho. Estante 65, caixa. 09, doc. 44. 
de março do mesmo ano. Ele, no entanto, alegava não ter se restabelecido desde o acidente e que antes do ocorrido era "valido, forte", e não apresentava "sintoma de qualquer doença". ${ }^{64}$

O advogado da seguradora, Nestor Duarte, contestava a ação, pois não considerava a lesão de natureza traumática nem agravada pelo traumatismo, uma vez que, contemporaneamente ao acidente, conforme laudo radiológico, o paciente já apresentava "modificação de transparência de ambos os vértices do pulmão por imagens nodulares". Ele ainda informou que o laudo radiológico havia sido entregue à Caixa de Aposentadoria de Transportes Urbanos, para facilitar a respectiva aposentadoria do trabalhador. ${ }^{65}$ Os peritos, entretanto, consideraram que o traumatismo não só havia revelado, mas agravado a tuberculose adquirida no exercício do trabalho. Estabeleceram também a correlação entre o estado de saúde do paciente e as condições de trabalho que exercia. Para eles, o trabalhador antes de sofrer o acidente, exercia suas atividades como fiscal de bonde aparentando boa saúde e mostrando equilíbrio entre a ação patogênica do bacilo e as defesas do organismo. ${ }^{66}$

A ação foi, então, julgada procedente, dando-se sentença favorável ao trabalhador. Não se conformando com o resultado, a seguradora recorreu ao Tribunal de Apelação do Estado da Bahia, mas o desembargador manteve a decisão inicial. Para ele, o conceito de acidente de trabalho não poderia ser restrito aos interesses econômicos do "mais forte", prejudicando "o lado fraco". Embora a tuberculose estivesse em "período de trégua", o acidente a colocou no seu "estado devastador". ${ }^{67}$ O processo foi concluído em janeiro de 1948. José Neri foi considerado portador de uma incapacidade total e permanente, recebendo a indenização e sendo aposentado pela Caixa a que estava associado. ${ }^{68}$

As mudanças na legislação de acidente de trabalho, ocorridas em 1934 e em 1944, ao ampliarem o conceito de acidente e de doença do trabalho, facilitaram o estabelecimento do nexo entre a tuberculose e o trabalho, inclusive possibilitando que os traumatismos pudessem ser considerados como agravantes ou desencadeantes dessa patologia. ${ }^{69}$

Dos processos de indenização que objetivavam a relação da tuberculose com o trabalho, três foram da Cia. Empório Industrial do Norte, um foi da Cia. Linha Circular, dois da Cia. Cessionária das Docas da Bahia, um da construtora Emílio Odebrecht, um do lacht Club da Bahia, e um da Newman e Cia., exportadora de couros. Em relação a essas duas últimas empregadoras, os únicos processos de indenização que encontramos, foram esses casos de tuberculose. Os dois casos ocorridos na Companhia Cessionária das Docas da Bahia foram os de Perciliano Oliveira e Fernando Evangelista de Jesus, comentados no início deste artigo.

Arlindo Manoel de Jesus, 32 anos, tecelão da Cia. Empório Industrial do Norte, procurou o médico da empresa, em 17 de janeiro de 1945, queixando-se de "fortes dores na face anterior do tórax", desencadeadas três dias antes, quando carregou um peso no trabalho. ${ }^{70}$ Após ter sido comunicado o ocorrido à autoridade competente, foi aberto o inquérito judicial. O exame de sanidade física, realizado pelos peritos em 4 de janeiro de 1946, confirmou o diagnóstico de tuberculose

64 APEB, Seção Judiciária, Acidente de Trabalho. Estante 65, caixa. 09, doc. 44, f. 3.

65 APEB, Seção Judiciária, Acidente de Trabalho. Estante 65, caixa. 09, doc. 44, f. 4.

66 APEB, Seção Judiciária, Acidente de Trabalho. Estante 65, caixa 09, doc. 44, f. 5.

67 APEB, Seção Judiciária, Acidente de Trabalho. Estante 65, caixa 09, doc. 44, f. 6.

68 APEB, Seção Judiciária, Acidente de Trabalho. Estante 65, caixa 09, doc. 44, f. 43-45.

69 BRASIL, Arquivo Judiciário. Decreto No 24.637, de 10 de julho de 1934; BRASIL, Legislação Federal. Decreto $\mathrm{n}^{\circ} 7.036$, de 10 de novembro de 1944, p. 377.

70 APEB, Seção Judiciária, Acidente de Trabalho. Estante 67, caixa 89, doc. 03. 
pulmonar produzida pelo exercício do trabalho ou em sua consequência. A ação foi julgada procedente e o processo foi concluído em 26 de setembro de 1946.

No ramo têxtil, a alta incidência de tuberculose tinha uma longa história. Em 1919, durante a greve geral ocorrida em Salvador, uma operária chegou a denunciar que as precárias condições de trabalho nas fábricas têxteis haviam matado seu pai e duas tias de tuberculose, adquiridas na Cia. Empório Industrial do Norte. ${ }^{71}$

Nessas fábricas, a lançadeira foi uma importante causadora de doenças. Era uma ameaça constante aos tecelóes que a levavam à boca para chupar o fio do tear. Além disso, possuía uma ponta fina que muitas vezes se desprendia, atingindo os trabalhadores. Olhos vazados, braços, mãos e dedos mutilados foram alguns dos acidentes por ela causados..$^{72}$ O Congresso Operário de 1913 pediu a extinção das lançadeiras e solicitou que fossem utilizados no Brasil processos de trabalho menos perigosos, como os vigentes na Europa.

Nas décadas de 1930 e 1940, em Salvador, as lançadeiras ainda eram utilizadas em estabelecimentos como a Cia. Empório Industrial do Norte, empresa que havia sido uma das mais importantes do ramo no Brasil. Nos nove processos que buscaram a relação da tuberculose com o trabalho, as sentenças foram favoráveis aos trabalhadores. Sete deles, no entanto, chegaram a óbito antes da sua conclusão.

\section{Considerações finais}

O estudo sobre acidentes e doenças de trabalho, realizado a partir dos processos de indenização, possibilitou conhecer uma pouco mais a classe trabalhadora de Salvador, nas décadas de 1930 e 1940. Os acidentados eram, em sua maioria, jovens e adultos conscientes de que as condições de trabalho eram danosas à saúde.

A documentação consultada mostrou a total despreocupação patronal com a melhoria dos ambientes de trabalho. Acidentes semelhantes na mesma empresa ocorreram ao longo do período estudado, sem que qualquer medida preventiva fosse adotada. Para receber a indenização os trabalhadores tinham, muitas vezes, que se submeter a longos e burocráticos processos. Apesar da previsão em lei, os empregadores só chegavam a cumpri-la mediante pressão. No momento em que o discurso governamental colocava-se como defensor do trabalho e dos trabalhadores, a partir de uma legislação social que os "amparava”, a realidade do trabalho sob a ótica de doenças e de acidentes, o desmistificava. Esse discurso não era acompanhado de ações efetivas de fiscalização e de controle dos ambientes de trabalho.

Para maioria dos trabalhadores, viver era estar na "corda bamba" entre a pobreza e a miséria. Era o trabalho, mesmo com baixa remuneração, que os tirava da última colocando-os na primeira. É provável que a ocorrência de doenças e de acidentes, mutilando ou reduzindo a capacidade de trabalho dos que labutavam, deixasse como alternativa para essas pessoas engrossar a fileira da mendicância nas ruas de Salvador. Foi no mundo do trabalho que o poder não conseguiu a harmonia e consenso social desejados. Mesmo com todo o controle exercido sobre o trabalhador, manifestações de insatisfação estiveram presentes. Tanto a

71 CASTELLUCCI. Industriais e operários baianos numa conjuntura de crise (1914-1921), p. 215.

72 HARDMAN, Francisco Foot; LEONARDI, Victor. História da Indústria e do Trabalho no Brasil. São Paulo: Global, 1982, p. 182. 
greve, como as estratégias cotidianas de resistência, presentes também nas ações de indenização, foram expressões de descontentamento.

Cabe lembrar a atualidade da temática abordada. Perciliano, Fernando, Virgílio, Francisca, Valdemar foram alguns, entre tantos outros, que tiveram a vida e a saúde comprometidas pelas precárias condições de trabalho, em Salvador, nas décadas de 1930 e 1940. As estatísticas atuais, guardadas as devidas especificidades, mostram que as doenças e os acidentes continuam sendo um trágico capítulo da história do trabalho.

Recebido em 20/06/2015 Aprovado em 21/11/2015 
